\title{
Determination of the gamma-ray effective dose from different cylindrical radioactive solution sources in a biological tissue by using Monte Carlo calculations
}

\author{
M.A. MISDAQ ${ }^{1}$, A. MERZOUKI ${ }^{1}$
}

(Manuscript received 27 March 2001, Accepted 9 February 2002)

\begin{abstract}
A new method was developed based on calculating the absorption coefficients, selfabsorption coefficients and transmission coefficients of the gamma-photons emitted by different radioisotopes for evaluating gamma dose equivalent rates, at 1 meter from various cylindrical radioactive solution sources utilized in medicine, in a biological tissue. Results obtained were compared with data given in literature. The influence of the radioisotope half-life and gamma-photon energy and number of photons per disintegration on the gamma dose equivalent rate, effective dose and threshold initial activity of the considered solution sources was studied.
\end{abstract}

RÉSUMÉ Détermination des doses gamma efficaces induites par des sources radioactives liquides de géométrie cylindrique dans un tissu biologique en utilisant la technique de calcul de Monte Carlo.

Une nouvelle méthode a été développée à partir du calcul des coefficients d'absorption, des coeflicients d'auto-absorption et des coefficients de transmission de photons gamma émis par différents radioisotopes; elle évalue les débits de doses gamma équivalents, à une distance de 1 mètre de diverses sources radioactives liquides utilisées en médecine, dans un tissu biologique. Les résultats obtenus ont été comparés à ceux obtenus par d'autres auteurs. L'influence de la période du radioélément, de l'énergie et de l'intensité des photons gamma émis sur le débit d'équivalent de dose, la dose efficace et l'activité initiale limite a été étudiée.

\section{Introduction}

Radioactive sources of gamma rays are increasingly utilized in various social and economical fields and more specifically for medical uses. The management of these radioactive material sources necessitates the control of radiation exposure to these sources. Many methods have been developed for evaluating gamma doses and gamma dose rates received by the users of such sources (Takadu and Kida, 1971; Unger and Trubey, 1982; ICRU 39, 1985; ICRP 51, 1987; ICRP 54, 1988;

\footnotetext{
${ }^{1}$ Nuclear Physics and Techniques Laboratory, Faculty of Sciences Scmlalia, BP 2390, University Cadi Ayyad, Marrakech, Morocco.

This work was realized under a PNC 11 PARS research contract with the CNCPRST, Rabat, Morocco.
} 
ICRU 43, 1988; Delacroix et al., 1994). Gamma-ray dose rates received by the skin of fingers of clinical and laboratory staff during injections of ${ }^{153} \mathrm{Sm}$ were calculated using a distributed point source approach (Pattison, 1999). Gamma dose rates from external exposure have been determined by many authors using analytical methods (Unger and Trubey, 1982; Delacroix et al., 1993; 1994). Monte Carlo calculations have been performed for evaluating gamma photon selfabsorption coefficients in different stainless steel samples (Rzama et al., 1994), determining annual absorbed gamma dose rates in an archaeological site (Misdaq et al., 1998a), characterizing stainless steel materials (Misdaq et al., 1997) and studying the influence of porosity on the radon emanation coefficient in different building materials (Misdaq et al., 1998b).

In this work, we describe a new calculation method based on exploiting the interaction processes of gamma photons emitted by different radioactive solution sources with the source material, air and a biological tissue for evaluating the resulting gamma-ray dose equivalent rates and gamma-ray effective doses at 1 meter from the source (Nachtigall, 1969; Kocher, 1981; Unger and Trubey, 1982 ) in the considered biological tissue.

\section{Methodology}

Let us consider a homogeneous radioactive solution source containing radionuclides emitting multienergetic gamma-rays. The considered source is packaged in a cylindrical glass container of $2.3 \mathrm{~cm}$ diameter and $2.5 \mathrm{~cm}$ height as shown in Figure 1. The resulting gamma dose equivalent rate in $\mathrm{Sv} \mathrm{h}^{-1}$, at a distance of 1 meter from the source, absorbed in a biological tissue (see Fig. 1) is given by:

$$
\dot{H}=A H_{\mathrm{sp}} \text {. }
$$

Here $A$ is the gamma initial activity per unit volume $\left(\mathrm{Bq} \mathrm{cm}^{-3}\right)$ of the radioactive solution source: for comparison with the results of Delacroix et al. (1994) an initial activity of $3.56 \mathrm{MBq} \mathrm{cm}^{-3}$ was utilized in our calculations and $H_{\mathrm{sp}}$ in $\mathrm{Sv} \mathrm{cm}$ is the specific gamma dose equivalent rate of the considered source at a distance of 1 meter, absorbed in the biological tissue, which is given by (Misdaq et al., 1998a; 2001):

$$
H_{\mathrm{sp}}=\frac{1}{d_{\mathrm{b}}} \sum_{i} I_{i} E_{i}(S A C)_{i}^{\mathrm{sol}}(T C)_{i}^{\mathrm{sol}}(A C)_{i}^{\mathrm{air}}(T C)_{i}^{\mathrm{air}}(A C)_{i}^{\mathrm{tiss}}
$$

where $d_{\mathrm{b}}$ is the biological tissue's density in $\mathrm{g} \mathrm{cm}^{-3}, I_{i}$ is the intensity of a gammaphoton of energy $E_{i}$ and index $i,(S A C)_{i}^{\text {sol }}$ is the self-absorption coefficient of a gamma-photon of energy $E_{i}$ and index $i$ in the radioactive source solution, 


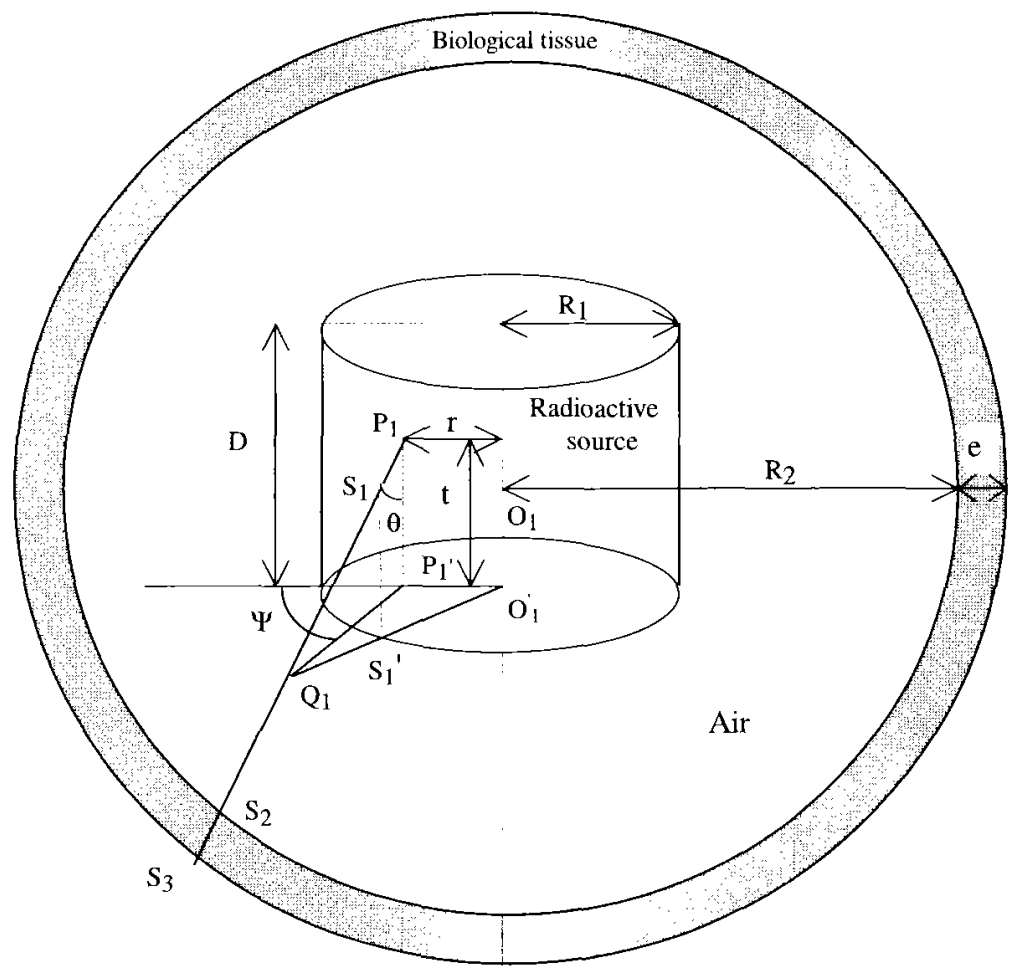

Figure 1 - Gamma-ray source-air absorber-biological tissue arrangement. The source has a radius $R_{I}=1.15 \mathrm{~cm}$, and height $D=2.5 \mathrm{~cm}$. The biological tissue has a height $e=0.3 \mathrm{~cm}$ and a density $d_{b}=1.04 \mathrm{~g} / \mathrm{cm}^{3}$ (ICRU 44, 1989).

Schéma de la disposition géométrique : source radioactive-air-tissu biologique. La source cylindrique a un rayon $R_{I}=1,15 \mathrm{~cm}$, une épaisseur $D=2,5 \mathrm{~cm}$. La couche du tissu biologique est $d^{\prime}$ une épaisseur $e=0,3 \mathrm{~cm}$ et une densité $d_{b}=1,04 \mathrm{~g} \mathrm{~cm}^{-3}$ (ICRU 44, 1989).

$(T C)_{i}^{\text {sol }}$ is the transmission coefficient of a gamma-photon of energy $E_{i}$ and index $i$ across the radioactive source solution, $(A C)_{i}^{\text {air }}$ is the absorption coefficient of a gamma-photon of energy $E_{i}$ and index $i$ in the air volume (see Fig. 1) surrounding the radioactive solution source, $(T C)_{i}^{\text {air }}$ is the transmission coefficient of a gamma-photon of energy $E_{i}$ and index $i$ across the air volume and $(A C)_{i}^{\text {tiss }}$ is the absorption coefficient of a gamma-photon of energy $E_{i}$ and index $i$ in the biological tissue assuming a bulk exposure of $300 \mathrm{mg}$ for each $\mathrm{cm}^{2}$ of the human body 
(ICRP 51, 1987). Thus, thickness of the biological tissue layer (Fig. 1) was chosen equal to $0.3 \mathrm{~cm}$.

The transmission and absorption probabilities of a gamma-photon generated from point $\mathrm{P}_{1}$ after crossing a path length $\ell_{1}=\mathrm{P}_{1} \mathrm{~S}_{1}$ in the radioactive solution source of radius $R_{\mathrm{l}}(\mathrm{cm})$, height $D(\mathrm{~cm})$ and density $d_{\mathrm{s}}\left(d_{\mathrm{s}}=1 \mathrm{~g} \mathrm{~cm}^{-3}\right)$ are given by:

$$
e^{-\mu_{1} \ell_{1}}
$$

and

$$
1-\mathrm{e}^{-\mu_{1} \ell}
$$

where $\mu_{1}$ in $\mathrm{cm}^{2} \mathrm{~g}^{-1}$ is the total attenuation coefficient of the gamma-photon in the radioactive solution source.

The transmission and absorption probabilities of the same gamma-photon in the spherical air volume of radius $R_{2}$ (in $\mathrm{cm}$ ) surrounding the radioactive solution source (Fig. 1) are given by:

$$
\mathrm{e}^{-\mu_{2} \ell_{2}}
$$

and

$$
1-\mathrm{e}^{-\mu_{2} \ell_{2}}
$$

where $\mu_{2}$ in $\mathrm{cm}^{2} \mathrm{~g}^{-1}$ is the total attenuation coefficient of the gamma-photon in the air volume and $\ell_{2}$ is the path length of the gamma photon in the air volume.

The absorption probability of the considered gamma-photon in a spherical layer of $0.3 \mathrm{~cm}$ height of the biological tissue placed at a distance of 1 meter around the radioactive solution source (Fig. 1) is given by:

$$
1-\mathrm{e}^{-\mu_{3} \ell_{3}}
$$

where $\mu_{3}$ in $\mathrm{cm}^{2} \mathrm{~g}^{-1}$ is the total attenuation coefficient of the gamma-photon in the biological tissue and $\ell_{3}$ is the path length of the gamma photon in the biological tissue.

The $\mu_{1}, \mu_{2}$ and $\mu_{3}$ coefficients have been evaluated by using data given by Hubbell and Seltzer (1995).

The random sampling of the emission point $\mathrm{P}_{1}$ and emission direction is achieved by computing the distance from the center $r$, the height $t, \cos \theta$ and $\cos \psi$ with four random numbers $\left(\xi_{1}, \xi_{2}, \xi_{3}\right.$ and $\left.\xi_{4}\right)$ (Misdaq et al., 1998a). Indeed, 
assuming uniform probability densities (homogeneous solution source) of the $\theta, r$, $t$ and $\psi$ parameters we get:

$$
\xi_{1}=\frac{\int_{0}^{r} r^{\prime} \mathrm{d} r^{\prime}}{\int_{0}^{R_{1}} r^{\prime} \mathrm{d} r^{\prime}}
$$

hence

$$
\begin{gathered}
r=R_{1} \sqrt{\xi_{1}} \quad 0 \leq \xi_{1}<1, \\
\xi_{2}=\frac{\int_{0}^{l} \mathrm{~d} x}{\int_{0}^{D} \mathrm{~d} x}
\end{gathered}
$$

then

$$
\begin{gathered}
t=D \xi_{2} \quad 0 \leq \xi_{2}<1, \\
\xi_{3}^{\prime}=\frac{\int_{0}^{\theta} \sin \theta^{\prime} \mathrm{d} \theta^{\prime}}{\int_{0}^{\pi / 2} \sin \theta^{\prime} \mathrm{d} \theta^{\prime}} \quad 0 \leq \xi_{3}^{\prime}<1
\end{gathered}
$$

thus

$$
\cos \theta=\xi_{3} \quad 0 \leq \xi_{3}<1
$$

and

then

$$
\xi_{4}=\frac{\int_{0}^{\psi} \mathrm{d} \varphi}{\int_{0}^{2 \pi} \mathrm{d} \varphi}
$$

$$
\psi=2 \pi \xi_{4} \quad 0 \leq \xi_{4}<1 .
$$

The path length $\ell_{1}$ is given by:

$$
\ell_{1}= \begin{cases}\frac{t}{\cos \theta} & \text { if } R_{1} \geq r_{1}^{\prime} \\ \ell(r, \theta, \psi) & \text { if } R_{1} \leq r_{1}^{\prime}\end{cases}
$$

where

$$
r_{1}^{\prime 2}={\overline{Q_{1}^{\prime}}}^{2} Q_{1}=r^{2}+t^{2} \tan ^{2}(\theta)+2 r t \tan (\theta) \cos (\psi)
$$


and

$$
\ell(r, \theta, \psi)=\frac{\sqrt{R_{1}^{2}-r^{2} \sin ^{2}(\psi)}-r \cos (\psi)}{\sin (\theta)}
$$

The calculation of the path length $\ell_{1}$ consists of generating random numbers by using a program called random subroutine based on a congruential method. The gamma-photons self-absorption coefficient in the radioactive solution source $(S A C)^{\text {sol }}$ and the transmission coefficient across the radioactive solution source $(T C)^{\text {sol }}$ are obtained for a large number $N$ of photons by the ratios of the appropriate sum of interaction probabilities and $N$ :

$$
(S A C)^{\mathrm{sol}}=\frac{1}{N} \sum_{i=1}^{N}\left(1-\mathrm{e}^{-\mu_{1} \ell_{1}^{i}}\right)
$$

and

$$
(T C)^{\mathrm{sol}}=\frac{1}{N} \sum_{i=1}^{N} \mathrm{e}^{-\mu_{1} \ell_{1}^{i}}
$$

The path length $\ell_{2}$ is given by:

$$
\ell_{2}= \begin{cases}\sqrt{\left(R_{2}^{2}-(D / 2)^{2}\right)-r_{1}^{\prime 2} \cos ^{2}(\theta)}-r_{1}^{\prime} \sin (\theta) & \text { if } R_{1} \geq r_{1}^{\prime}, \\ \frac{1}{\sin (\theta)}\left[\sqrt{\left(R_{2}^{2}-(D / 2)^{2}\right)-r^{2} \sin ^{2}(\psi)}-\sqrt{R_{1}^{2}-r^{2} \sin ^{2}(\psi)}\right] & \text { if } R_{1}<r_{1}^{\prime} .\end{cases}
$$

The gamma-photons absorption coefficient in the air volume $(A C)^{\text {air }}$ and transmission coefficient across the air volume $(T C)^{\text {air }}$ are obtained for a large number $N$ of photons by:

$$
(A C)^{\mathrm{air}}=\frac{1}{N} \sum_{i=1}^{N}\left(1-\mathrm{e}^{-\mu_{2} \ell_{2}^{i}}\right)
$$

and

$$
(T C)^{\mathrm{air}}=\frac{1}{N} \sum_{i=1}^{N} \mathrm{e}^{-\mu_{2} \ell_{2}^{i}}
$$


The path length $\ell_{3}$ is given by:

$$
\begin{aligned}
& \ell_{3}= \\
& \begin{cases}\sqrt{\left(R_{3}^{2}-(D / 2)^{2}\right)-r_{1}^{\prime 2} \cos ^{2}(\theta)}-\sqrt{\left(R_{2}^{2}-(D / 2)^{2}\right)-r_{1}^{\prime 2} \cos ^{2}(\theta)} & \text { if } R_{1} \geq r_{1}^{\prime} \\
\frac{1}{\sin (\theta)}\left[\sqrt{\left(R_{3}^{2}-(D / 2)^{2}\right)-r^{2} \sin ^{2}(\psi)}-\sqrt{\left(R_{2}^{2}-(D / 2)^{2}\right)-r^{2} \sin ^{2}(\psi)}\right] & \text { if } R_{1}<r_{1}^{\prime}\end{cases}
\end{aligned}
$$

where $R_{3}=R_{2}+e$. $e$ is the height of the biological tissue layer (Fig. 1).

The gamma-photons absorption coefficient in the biological tissue is obtained for a large number $N$ of photons by:

$$
(A C)^{\text {tiss }}=\frac{1}{N} \sum_{i=1}^{N}\left(1-\mathrm{e}^{-\mu_{3} \ell_{3}^{i}}\right) .
$$

Results obtained for the gamma-photons self-absorption, absorption and transmission coefficients are given in Table I. The statistical uncertainty of the gamma-rays self-absorption, absorption and transmission coefficients is of $0.5 \%$.

The gamma effective dose absorbed in the biological tissue during a time interval $t_{2}$ is given by:

$$
E=w_{\mathrm{T}} \frac{\int_{00}^{t_{1} t_{2}} H(t) \mathrm{d}^{2} t}{\int_{0}^{t_{2}} \mathrm{~d} t}
$$

where $w_{\mathrm{T}}=1$ is the human body weighting factor (ICRP 51, 1987) and $\dot{H}(t)=A \mathrm{e}^{-\lambda t} H_{\mathrm{sp}}$ is expressed in $\mathrm{Sv} \mathrm{h}^{-1} . \lambda$ is the radioactive decay constant in $\mathrm{h}^{-1}$ of the radioisotope. $A$ is the initial activity per unit volume of the radioactive solution source $\left(\mathrm{Bq} \mathrm{cm}{ }^{-3}\right) \cdot t_{1}=1000 \mathrm{~h}$ is the exposure time; the proposed exposure time of $1000 \mathrm{~h}$ assumes the source exposes someone $8 \mathrm{~h} \mathrm{~d}^{-1}, 5 \mathrm{~d} \mathrm{wk}^{-1}$, over a 6-mo period. $t_{2}$ is the decay time of the radioisotope which is equal to $4380 \mathrm{~h}$ $\left(24 \mathrm{~h} \mathrm{~d}^{-1} \times 30.4 \mathrm{~d} \mathrm{mo}^{-1} \times 6 \mathrm{mo}\right)$ (Shingelton, 1998). By integrating equation (26), we get:

$$
E=w_{\mathrm{T}} A H_{\mathrm{sp}} \frac{t_{1}\left(1-\mathrm{e}^{-\lambda t_{2}}\right)}{\lambda t_{2}} .
$$




\section{TABLE I}

Energy $E_{i}$, intensity $I_{i}$, gamma-ray self-absorption coefficient $(S A C)_{i}^{\text {sol }}$ and transmission coefficient $(T C)_{i}^{\text {sol }}$ in the solution source, gamma-ray absorption coefficient $(A C)_{i}^{\text {air }}$ and transmission coefficient $(T C)_{i}^{\text {air }}$ in the air volume and gamma-ray absorption coefficient in the biological tissue $(A C){ }_{i}^{\text {tiss }}$ for the ${ }_{61}^{24} \mathrm{Na},{ }_{13}^{26} \mathrm{Al},{ }_{19}^{40} \mathrm{~K},{ }_{26}^{52 \mathrm{~m}} \mathrm{Mn}$ and ${ }_{25}^{56} \mathrm{Mn}$ radionuclides (a) and ${ }_{26}^{59} \mathrm{Fe}$, ${ }_{30}^{65} \mathrm{Zn},{ }_{31}^{66} \mathrm{Ga},{ }_{27}^{60} \mathrm{Co}$ and ${ }_{37}^{86} \mathrm{Rb}$ radionuclides (b).

Énergie $E_{i}$, intensité $\boldsymbol{I}_{i}$, coefficient d'auto-absorption $(S A C)_{i}^{\text {sol }}$ et coefficient de transmission $(T C)_{i}^{\text {sol }}$ dans la solution source, coefficient d'absorption $(A C)_{i}^{\text {air }}$ et coefficient de transmission

$(T C)_{i}^{\text {air }}$ dans le volume d'air et coefficient d'absorption dans le tissu biologique $(A C)_{i}^{\text {tiss }}$ des photons gamma émis par les radioisotopes ${ }_{11}^{24} \mathrm{Na},{ }_{13}^{26} \mathrm{Al},{ }_{19}^{40} \mathrm{~K},{ }_{25} \mathrm{~m} / \mathrm{Mn}$ et ${ }_{25}^{56} \mathrm{Mn}$ (a) et les radioisotopes ${ }_{26}^{59} \mathrm{Fe},{ }_{30}^{65} \mathrm{Zn},{ }_{31}^{66} \mathrm{Ga},{ }_{27}^{60} \mathrm{Co}$ et ${ }_{37}^{86} \mathrm{Rb}$ (b).

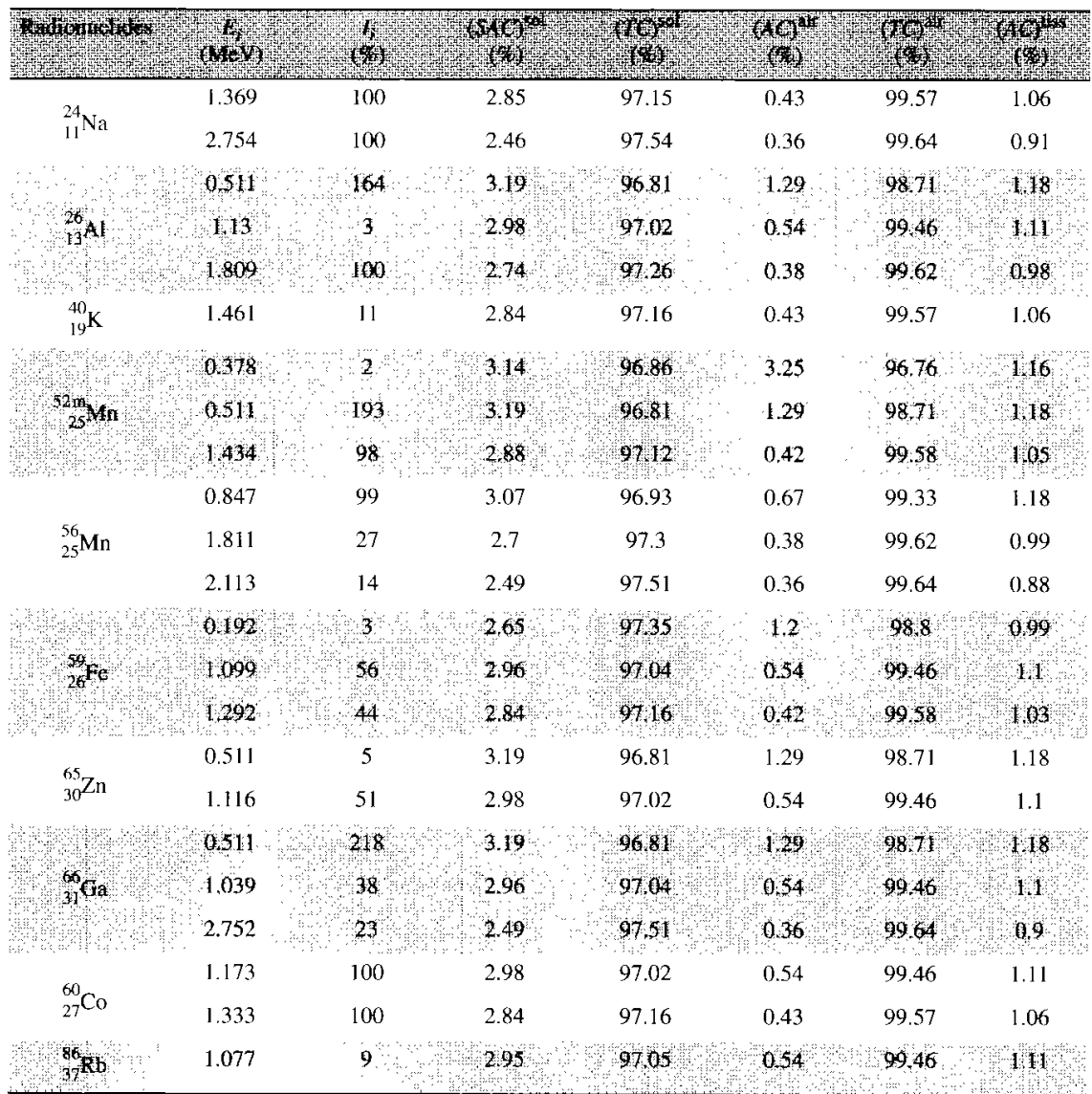


TABLE II

Data obtained for the gamma-ray dose equivalent rate at 1 meter, absorbed in a biological tissue, from different solution sources.

Résultats du calcul des taux d'équivalents de doses gamma absorbées dans le tissu biologique situé à une distance de 1 mètre pour les différents radioisotopes étudiés.

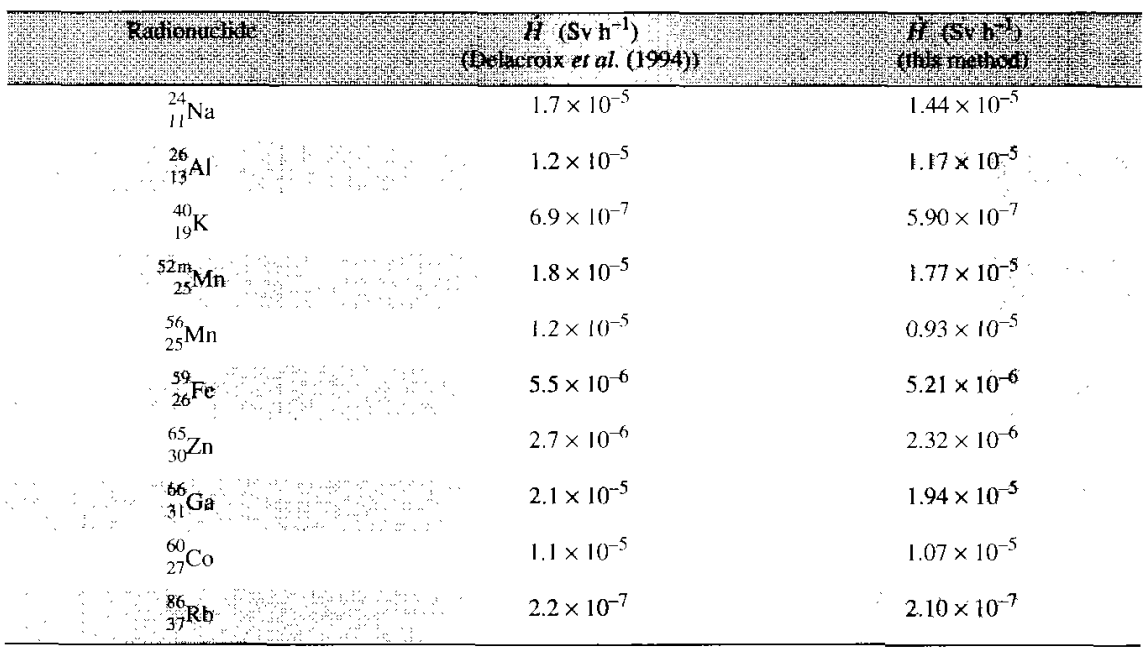

\section{Results and discussion}

The self-absorption, absorption and transmission coefficients of gamma-photons emitted by radionuclides contained in different radioactive solution sources have been evaluated (Tab. I). The gamma dose equivalent rate $H$ has been determined at 1 meter from various radioactive solution sources and absorbed in a biological tissue. Data obtained are shown in Table II. Data obtained for the gamma dose equivalent rate are in agreement with those given by Delacroix et al. (1994) (Tab. II) for the same solution sources and the same biological tissue. This Monte Carlo calculation method has the advantages of being accurate (the statistical uncertainty of the gamma dose equivalent rate determination is of $1 \%$ ), rapid (a few seconds calculation time) and is performed on a simple PC compared to the analytical method used by Delacroix et al. (1994). The gamma effective dose $E$ corresponding to a ( $8 \mathrm{~h} \mathrm{~d}^{-1}, 5 \mathrm{~d} \mathrm{wk}^{-1}$, over a 6 -mo period) external exposure of a worker has been evaluated for different radioactive solution sources. According to equation (27), we notice that for long-lived radioisotopes $\left({ }_{13}^{26} \mathrm{Al}\right.$ and $\left.{ }_{19}^{40} \mathrm{~K}\right) E$ varies linearly as a function of time $t$ since the $\left(1-\mathrm{e}^{-\lambda t_{2}}\right) / \lambda t_{2}$ factor is equal to 1 . For the other sources containing radionuclides with half-lives on the order of days to a few years that factor is smaller than 1 . We notice that ${ }_{13}^{26} \mathrm{Al}$ and ${ }_{27}^{60} \mathrm{Co}$ source show 


\section{TABLE III}

Data obtained for the gamma effective dose $(E)$ absorbed in a biological tissue and threshold initial activity $\left(A^{\text {th }}\right)$ for different solution sources.

Résultats du calcul des doses gamma efficaces absorbées dans le tissu biologique $(E)$ ainsi que les activités gamma initiales limites $\left(A^{\text {th }}\right)$ pour les solutions radioactives étudiés.

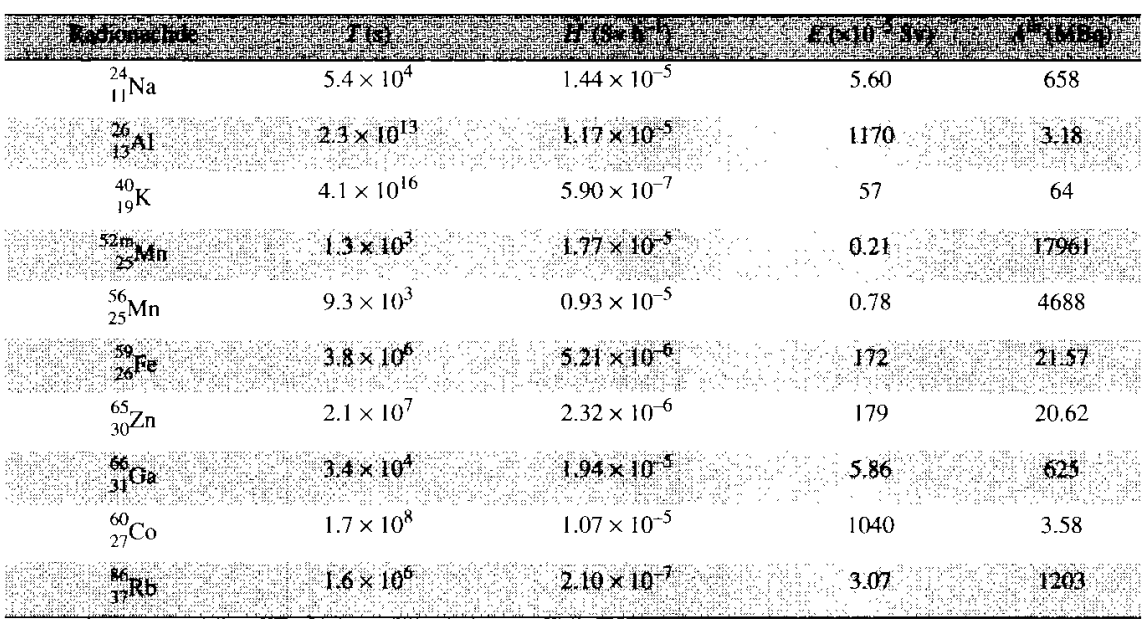

higher gamma effective doses than the other solution sources. It is due to the fact that these two sources present higher half-life and higher gamma-ray intensities than the other sources (Tabs. I and III).

The threshold initial activity $\left(A^{\text {th }}\right)$ corresponding to a gamma effective dose limit of $1 \mathrm{mSv}$ (Shingelton, 1998) have been determined for the radioactive solution sources studied. Data obtained are shown in Table III.

The considered ${ }^{40} \mathrm{~K},{ }^{24} \mathrm{Na},{ }^{52 \mathrm{~m}} \mathrm{Mn},{ }^{56} \mathrm{Mn},{ }^{66} \mathrm{Ga}$ and ${ }^{86} \mathrm{Rb}$ solution sources, with initial activities of $3.56 \mathrm{MBq} \mathrm{cm}^{-3}$, do not present a great danger for the users of these sources since their threshold initial activities corresponding to the gamma effective dose limit of $1 \mathrm{mSv}$ are too high (Tab. III). The ${ }^{59} \mathrm{Fe},{ }^{26} \mathrm{Al},{ }^{65} \mathrm{Zn}$ and ${ }^{60} \mathrm{Co}$ solution sources of $3.56 \mathrm{MBq} \mathrm{cm}^{-3}$ initial activities could present a danger for the users because their threshold initial activities are relatively low (Tab. III). Indeed, small activities could induce high gamma effective doses. We also notice that the influence of the half-life of the radioisotope contained in the solution source on the threshold initial activity $\left(A^{\text {th }}\right)$ is important. Indeed, when the half-life of the radioisotope increases the threshold activity $A^{\text {th }}$ decreases: for radioisotopes of short half-lives the radioactive disintegration is important and the threshold activity corresponding to a gamma effective dose of $1 \mathrm{mSv}$ is higher than for radioisotopes of long half-lives. However, for the ${ }_{13}^{26} \mathrm{Al}$ and ${ }_{19}^{40} \mathrm{~K}$ solution sources 
the number of the emitted gamma-rays and their corresponding intensities are predominant: the ${ }_{13}^{26} \mathrm{Al}$ solution source (three $\gamma$-rays) presents a smaller threshold initial activity corresponding to a gamma effective dose of $1 \mathrm{mSv}$ than the ${ }_{19}^{40} \mathrm{~K}$ solution source (only one $\gamma$-ray of $11 \%$ intensity).

\section{Conclusion}

It has been shown by this study that by Monte Carlo simulations of the interaction processes of the gamma-rays emitted by different radioisotopes inside cylindrical solution sources one can evaluate the gamma-ray dose equivalent rates and gamma-ray effective doses at 1 meter from these sources in a biological tissue. The threshold initial activity corresponding to a gamma effective dose of $1 \mathrm{mSv}$ has been determined for the solution sources studied. It has been shown those solution sources containing radioisotopes of long half-life show smaller threshold initial activities and consequently present a higher danger to the users than those containing radionuclides of short half-lives. This calculation method which is accurate, rapid (a few seconds calculation time) and can be performed on a simple $\mathrm{PC}$, is a good tool for the control and management of solution sources.

\section{REFERENCES}

Delacroix D., Chazot C., Guerre J.P. (1993) Calcul des débits de doses $\beta$ et $\gamma$ en fonction de la géométrie de la source, CE-Saclay, DSCE/SRI-A/93-32.

Delacroix D., Guerre J.P., Leblanc P. (1994) Radionuclides et radioprotection, CE-Saclay, pp. 31-69.

Hubbell J.H., Seltzer S.M. (1995) Tables of X-ray mass attenuation coefficients and mass energyabsorption coefficients $1 \mathrm{keV}$ to $20 \mathrm{MeV}$ for $Z=1$ to 92 and 48 addition substances of dosimetric interest, NISTIR 5632.

ICRP Publication 51 (1987) Data for use in radioprotection against external radiation, Ann. ICRP 17 (2/3).

ICRP Publication 54 (1988) Individual monitoring for intakes of radionuclides by workers: design and interpretation, Ann. ICRP 19 (1-3).

ICRU Report 39 (1985) Determination of dose equivalents resulting from external radiation sources, Bethesda, MD.

ICRU Report 43 (1988) Determination of dose equivalents from external radiation sources - Part 2 , Bethesda, MD.

ICRU Report 44 (1989) Tissue substitutes in radiation dosimetry and measurement, Bethesda, MD.

Kocher D.C. (1981) Radioactive Decay Data Tables: A Handbook of decay data for application to radiation dosimetry and radiological assessments, U.S. Dept. of Energy, DOE / TIC-1 1026.

Misdaq M.A., Charik R., Blondiaux G. (1997) Characterization of stainless stell materials using experimental and calculational methods, Radiat. Phys. Chem. 49, 195-205.

Misdaq M.A., Fahde K., Erramli H., Mikdad A., Rzama A., Yousfi Charif M.L. (1998a) A new method for evaluating annual absorbed gamma dose rates in an archaeological site by combining the SSNTD technique with Monte Carlo simulations, Radiat. Phys. Chem. 53, 377-384. 
Misdaq M.A., Khajmi H., Ktata A. (1998b) Study of the influence of porosity on the radon emanation coefficient in building material samples by combining the SSNTD technique with the Monte Carlo simulations, Radiat. Phys. Chem. 53, 385-390.

Misdaq M.A. Merzouki A., Elabboubi D., Sfairi T. (2001) A new method for studying the transport of $\gamma$ photons in various geological material by combining the SSNTD technique with Monte Carlo simulations, Radiat. Meas. 33 (2), 175-181.

Nachtigall D. (1969) Table of Specific Gamma-Ray Constants, Verlag Karl Thiemig KG, Munich.

Pattison J.E. (1999) Finger doses received during ${ }^{153}$ Sm injections, Health Phys. 77 (5), 530-535.

Rzama A., Misdac M.A., Erramli H., Blondiaux G., Isabelle D.B., Bajard J.C. (1994) Study of gammaphoton self-absorption in stainless stell samples by experimental and calculational methods, J. Radioanal. Nucl. Chem. 183, 409-420.

Shingelton K.L., Lee D.W. (1998) Radioactive sealed source accountability - A risk-based approach, Health Phys. 74 (4), 435-44l.

Takadu Y., Kida T. (197I) Radiation dose to skin and bone of fingers from handling radioisotopes in a syringe, Health Phys. 22, 295-297.

Unger L.M., Trubey D.K. (1982) Specific gamma-ray dose constants for nuclides important to dosimetry and radiological assessment, Oak Ridge National Laboratory, RSIC-45 / R I. 